\title{
Clarification of Relationship Between Projective Tests and Questionnaires
}

\author{
Shogo Komatsu *, Koichiro Aoki ${ }^{\dagger}$, Chieko Kato ${ }^{\dagger}$
}

\begin{abstract}
Although questionnaire-based quantitative surveys can be implemented quickly and efficiently for groups, they are also known to have challenges, such as limited contents and skewed results due to intentional responses of the survey targets. In this regard, the projection method can be used to deeply understand the internal aspects of a client, including his/her unconscious side. If the relationship between the questionnaire and the projection methods can be shown and the classification of the psychological aspects that each method measures can be clarified, then the significance of the assessment that combines multiple methods will become more evident. In this study, we conducted a survey by using the combination of the Baum Test and the Group TAT, which was developed for group use based on TAT, one of the projection methods, together with SRS-18, which is a scale to measure stress reaction. We clarified the relationship between the tests and evaluated the psychological aspects covered in each test by analyzing the correlation among the measured aspects. This study was conducted with the cooperation of Kenta Koshimura, Ren Yamamura, and Takuya Oizumi, who are graduates of the Faculty of Information Sciences and Arts Toyo University.
\end{abstract}

Keywords: psychological assessment, projective test, questionnaire, statistical analysis

\section{Introduction}

One of the social problems that exist in Japan is the need to deal with mental health problems due to the high percentage of workers who experience intense anxiety, doubt, and stress (Ministry of Health, Labor and Welfare, 2016). In 2014, the number of mental health patients had reached nearly 4 million (Ministry of Health, Labor and Welfare, 2014), and it can be said that early detection of such disorders in workplaces and schools and dealing with stress that causes the conditions are important issues that need to be addressed. Since December 2015, there have been concrete measures in place to understand the psychological state of each person, such as the obligation to conduct stress checks in workplaces with 50 workers or more. Stress tests to screen

\footnotetext{
* Yokohama City University Medical Center / Toyo University Kanagawa / Saitama, Japan

$\dagger$ Toyo University Saitama, Japan
} 
for mental health disorders are usually conducted in the form of paper-based or online questionnaires and are analyzed quantitatively at each workplace.

Although questionnaire-based quantitative surveys can be implemented quickly and efficiently for groups, they are also known to have challenges, such as limited contents and skewed results due to intentional responses of the survey targets. In this regard, the projection method can be used to deeply understand the internal aspects of a client, including his/her unconscious side, and has been used in the field of clinical psychology. The projection method presents language or visual stimulus to a client, who responds by performing an expressive action, thus eliciting a free response that can be used to measure the personality traits of the client. Since the survey results are obtained as qualitative data in the form of texts or drawings, they characteristically require high expertise to be analyzed and interpreted.

For example, the Baum Test, which is one of the projection drawing methods, has been used extensively in the clinical setting, and the insights from the test are useful in the attempt to understand the client. In the medical field, it has been used as one of the psychological tests for mental health patients to be used as an indicator of differential diagnosis and changes in pathological condition. The procedure is simple, does not generate much resistance, is not mediated by language, and others, so the test does not impose any significant burden on the patient. In Japan, this test has many case studies with a broad range of application, such as in examining the pathogenesis and recovery process of schizophrenic patients (Mukuta, Komiya, 2005) [1], using a drawing method for children with developmental disorders (Murakami, 2011) [2], and many others.

As described above, psychological tests are often used to provide actual support for clients, and an assessment that combines multiple methods, such as questionnaire and projection methods, is preferred to understand the psychological traits and problems of individuals further. However, it has not been easy to combine such methods. The reasons are that it is difficult to interpret the results of the test that uses the projection method, and the relationship of such methods with other psychometric scales still needs to be evaluated further. In the previous studies that focused on the relationship between psychometric scales and the projection method, the YG personality test and the Baum Test were compared, and the relationships between the personality traits and the Baum Test indicators (Tsunashima, 1992) [3], trunk and crown, landscape accessories (Ito et al., 2008) [4], and others, were suggested. If the relationship between the questionnaire and the projection methods can be shown and the classification of the psychological aspects that each method measures can be clarified, then the significance of the assessment that combines multiple methods will become more evident.

In this study, we conducted a survey by using the combination of the Baum Test and the Group TAT, which was developed for group use based on TAT, one of the projection methods, together with SRS-18, which is a scale to measure stress reaction. We clarified the relationship between the tests and evaluated the psychological aspects covered in each test by analyzing the correlation among the measured aspects. 


\section{Method}

\section{A. Survey Period}

The survey was conducted for two days in October 2018 in the classroom inside A University.

\section{B. Subjects}

The subjects were 29 students (14 males and 15 females, 20-25 years old) of A University.

C. Psychological Test

The subjects were asked to respond to three types of psychological tests as follows.

1) Baum Test (Three-sheet method): The Baum Test, which was systematized by Koch (1957), is one of the projection methods where the test subject draws a tree on a paper, and have his/her conscious and unconscious mental conditions revealed from the characteristics of picture. In this study, we used the three-sheet method that was proposed by Castilla (2002) among the available variations of the Baum Test. In this method, the subject draws three types of tree, which were then examined comparatively to interpret and analyze the subject's personality tendency and problematic behaviors. The subjects were given A4-size drawing papers and a $2 \mathrm{~B}$ pencil and were asked to draw three kinds of trees consecutively according to the following instructions (First sheet: Please draw a tree. Second sheet: Please draw a tree. You can draw the same tree as the first one or another tree. Third sheet: Please draw a tree of your dream, or the most beautiful tree for you; a tree that you want to plant on your backyard if you can, the most memorable tree for you, or a tree based on your imagination.) Also, the subjects were instructed to place the paper in a portrait orientation when drawing. The total length of the tree together with the sizes of the trunk and crown were measured and used for analysis. If the top of the tree was drawn out of the paper, the top side of the paper was considered as the top of the tree, and if the bottom of the tree was drawn out of the paper, the bottom of the paper was considered as the root of the tree.

2) Thematic Apperception Test (TAT): Thematic apperception test (TAT) is a type of projective test that was first reported by Morgan and Murray (1935). This test is based on Murray's (1938) desire-pressure theory and tries to understand a person's personality based on the episodes that arise from the relationship between the individual's internal desires and the external pressure exerted by the environment on the person. The subject is asked to freely create a story by looking at pictures that can be interpreted in various ways. In this study, we used the Group TAT Test, which was developed to conduct TAT, which is supposed to be an individualized test, to a group. As the measured items in the Group TAT Test, five items related to desire (P: Power, AF: Affection, SA: Social Approval, B: Belonging, IP: Independence) and three items related to reaction (AG: Aggression, R: Regression, F: Fantasy), three items related to outcome (H: Happy, U: Unhappy, IF: Indefinite), and three items related to livelihood domains (S: Social Domain, F: Family Domain, F: Self Domain) were calculated and used for analysis.

3) Psychological Stress Response Scale (SRS-18): The psychological stress response scale (Stress Response Scale-18: SRS-18) is a scale that can multilaterally measure a person's "psychological stress response" in stressful situations experienced in daily life. In this study, we conducted a questionnaire survey using SRS-18 to clarify the relationship between the traits 
revealed from the projection method's evaluation result and the stress situation of the subject. The measured items were the same as those in the questionnaire, which are "Depression and anxiety", "Irritability and anger", and "Helplessness", and their total scores were calculated and used for analysis.

The "Baum test" is the most frequently used projection method, so it is adopted this time. Also related to that is "TAT", a test also often utilized in other aspects like the administration of justice. Yet, there are insufficient reports about the relationship between TAT and other projection methods. The "interpretation method" depends heavily on the experience of the inspector so it is adopted this time.

The execution of individual TAT takes 1-2 hours, and same time execution on multiple subjects is not feasible but collective TAT only needs 45 minutes for simultaneous test on multiple subjects, so it is adopted this time.

Regarding SRS-18, this test was adopted for measuring stress response because the number of items is as small as 18 , along with the small burden on the subjects.

4) Analysis Method: Correlation analysis was performed between the measurement items obtained by the above-mentioned psychological test, and the relationship between the items for which the significant correlation coefficient was obtained was considered.

\section{Results}

\section{A. Psychological Test Results}

The measured values obtained by the Baum test (Table 1), Group TAT (Table 2), and SRS-18 (Table 3), and the score of each item are shown below.

\section{B. Analysis Results}

Tables 4 and 5 show the results of correlation analysis that was performed on the measured items of the Baum Test against those of Group TAT and SRS-18, respectively.

For Baum Test's Total Length, Trunk, and Crown, only the measured values in the first sheet correlated with the measured items of the Group TAT and SRS-18. The measured values in the second and third sheets did no correlate with the other psychological tests.

The Total Length of the drawings on the first sheet had a positive correlation with Group TAT's Social Approval (SA: $r=.40, p<.05$ ) and Society (S: $r=.40, p<.05$ ), and a negative correlation with Group TAT's Independence (IP: $r=-.45, p<.05)$, as well as with SRS-18's Irritability, anger $(r$ $=-.56, p<.01)$ and Total Score $(r=-.39, p<.05)$. Furthermore, the Trunk had a negative correlation with Group TAT's Happiness (H: $r=-.37, p<.05)$ and SRS-18 's Irritability, anger $(r=-.42, p<.05)$. The Crown correlated positively with Group TAT's Belonging (B: $r=.53, p<.01$ ), Society (S: $r=.56, p<.01$ ), Independence (IP: $r=-.43, p<.05$ ), and Home (H: $r=-.47, p<.01)$.

A negative correlation between irritability and anger in SRS-18 and regression in Group TAT (R: $r=-.42, p<.05)$ was observed. In addition, Helplessness of SRS-18 was observed to have a positive correlation with Home of Group Tat (H: $r=.41, p<.05)$, and a negative correlation with Society (S: $r=-.38, p<05)$. 
Table 1: Measurement Results of the Pictures in Baum Test

\begin{tabular}{|c|c|c|c|}
\cline { 2 - 4 } \multicolumn{1}{c|}{} & \multicolumn{3}{c|}{ First Sheet } \\
\cline { 2 - 4 } & $\begin{array}{c}\text { Total } \\
\text { Length }\end{array}$ & Trunk & Crown \\
\hline $\begin{array}{c}\text { Average } \\
\text { (cm) }\end{array}$ & 24.34 & 14.09 & 13.37 \\
\hline \multirow{2}{*}{ SD } & 5.82 & 4.88 & 4.72 \\
\hline \multirow{2}{*}{} & \multicolumn{3}{|c|}{ Second Sheet } \\
\cline { 2 - 4 } \multicolumn{1}{c|}{$\begin{array}{c}\text { Total } \\
\text { Length }\end{array}$} & Trunk & Crown \\
\hline SD & 22.28 & 11.49 & 12.66 \\
\hline \multirow{2}{*}{ SD } & 7.69 & 4.32 & 5.06 \\
\hline & $\begin{array}{c}\text { Total } \\
\text { Tength }\end{array}$ & Trunk & Crown \\
\hline $\begin{array}{c}\text { Average } \\
(\mathrm{cm})\end{array}$ & 24.16 & 12.31 & 12.99 \\
\hline SD & 5.73 & 4.32 & 4.87 \\
\hline
\end{tabular}

Table 2: Scores of the Items in Group TAT

\begin{tabular}{|c|c|c|c|c|c|}
\hline \multicolumn{6}{|c|}{ Desire } \\
\hline & Power $(P)$ & $\begin{array}{l}\text { Affection } \\
\quad(A F)\end{array}$ & $\begin{array}{c}\text { Social } \\
\text { Approval } \\
(S A)\end{array}$ & $\begin{array}{l}\text { Belonging } \\
\text { (B) }\end{array}$ & $\begin{array}{c}\text { Independence } \\
(I P)\end{array}$ \\
\hline Average & 55.93 & 49.24 & 55.86 & 50.14 & 41.38 \\
\hline SD & 10.09 & 9.39 & 7.27 & 9.09 & 8.54 \\
\hline \multicolumn{6}{|c|}{ Reaction } \\
\hline & $\begin{array}{c}\text { Aggression } \\
(A G)\end{array}$ & $\begin{array}{l}\text { Regression } \\
(R)\end{array}$ & $\begin{array}{c}\text { Fantasy } \\
(F)\end{array}$ & & \\
\hline Average & 44.72 & 54.93 & 51.34 & & \\
\hline SD & 7.86 & 7.73 & 7.34 & & \\
\hline \multicolumn{6}{|c|}{ Outcome } \\
\hline & Happy $(H)$ & $\begin{array}{c}\text { Unhappy } \\
(U)\end{array}$ & $\begin{array}{c}\text { Indifinite } \\
(I F)\end{array}$ & & \\
\hline Average & 54.03 & 46.72 & 49.52 & & \\
\hline SD & 9.82 & 9.85 & 11.43 & & \\
\hline \multicolumn{6}{|c|}{ Livelihood domain } \\
\hline & Society $(S)$ & Home $(H)$ & $\operatorname{Self}(F)$ & & \\
\hline Average & 57.48 & 42.52 & 49.38 & & \\
\hline SD & 12.49 & 10.64 & 10.84 & & \\
\hline
\end{tabular}


Table 3: Scores of the Measured Items in SRS-18

\begin{tabular}{|c|c|c|c|c|}
\hline & $\begin{array}{c}\text { Depression, } \\
\text { Anxiety }\end{array}$ & $\begin{array}{c}\text { Irritability, } \\
\text { Anger }\end{array}$ & Helplessness & Total Score \\
\hline Average & 3.76 & 2.79 & 5.52 & 12.07 \\
\hline SD & 3.77 & 2.94 & 3.46 & 9.14 \\
\hline
\end{tabular}

Table 4: Correlation Analysis Results (1)

\begin{tabular}{|c|c|c|c|c|}
\hline \multirow{2}{*}{ Scale } & \multirow[b]{2}{*}{ Factor } & \multicolumn{3}{|c|}{ First Sheet } \\
\hline & & $\begin{array}{c}\text { Total } \\
\text { Length }\end{array}$ & Trunk & Crown \\
\hline \multirow{5}{*}{$\begin{array}{l}\text { Group TAT } \\
\text { (Desire) }\end{array}$} & $\mathrm{P}$ & -.15 & -.32 & -.19 \\
\hline & $\mathrm{AF}$ & .14 & .29 & .08 \\
\hline & SA & $.40^{*}$ & .30 & .16 \\
\hline & B & .27 & -.09 & $.53 * *$ \\
\hline & IP & $-.45^{*}$ & -.01 & $-.43 *$ \\
\hline \multirow{3}{*}{$\begin{array}{l}\text { Group TAT } \\
\text { (Reaction) }\end{array}$} & $\mathrm{AG}$ & -.31 & -.32 & -.06 \\
\hline & $\mathrm{R}$ & .16 & .27 & -.03 \\
\hline & $\mathrm{F}$ & .16 & .05 & .12 \\
\hline \multirow{3}{*}{$\begin{array}{l}\text { Group TAT } \\
\text { (Outcome) }\end{array}$} & $\mathrm{H}$ & -.02 & $-.37 *$ & .03 \\
\hline & $\mathrm{U}$ & .11 & .12 & .02 \\
\hline & IF & -.10 & .16 & -.08 \\
\hline \multirow{3}{*}{$\begin{array}{l}\text { Group TAT } \\
\text { (Livelihood } \\
\text { domain) }\end{array}$} & $S$ & $.40^{*}$ & .05 & $.56 * *$ \\
\hline & $\mathrm{H}$ & -.34 & .02 & $-.47 * *$ \\
\hline & $\mathrm{F}$ & -.20 & -.06 & -.21 \\
\hline \multirow{4}{*}{ SRS-18 } & $\begin{array}{c}\text { Depression, } \\
\text { Anxiety }\end{array}$ & -.30 & -.31 & -.08 \\
\hline & $\begin{array}{l}\text { Irritability, } \\
\text { Anger }\end{array}$ & $-.56 * *$ & $-.42 *$ & -.30 \\
\hline & Helplessness & -.24 & -.16 & -.10 \\
\hline & Total Score & $-.39 *$ & -.32 & -.17 \\
\hline
\end{tabular}

$*: p<.05, * *: p<.01$ 
Table 5: Correlation Analysis Results (2)

\begin{tabular}{|c|c|c|c|c|c|}
\hline \multirow[b]{2}{*}{ Scale } & \multirow{2}{*}{ Factor } & \multicolumn{4}{|c|}{ SRS-18 } \\
\hline & & $\begin{array}{c}\text { Depression, } \\
\text { Anxiety }\end{array}$ & $\begin{array}{c}\text { Irritability, } \\
\text { Anger }\end{array}$ & Helplessness & $\begin{array}{l}\text { Total } \\
\text { Score }\end{array}$ \\
\hline \multirow{5}{*}{$\begin{array}{c}\text { Group TAT } \\
\text { (Desire) }\end{array}$} & $\mathrm{P}$ & -.02 & .08 & .08 & 0.05 \\
\hline & $\mathrm{AF}$ & -.07 & -.23 & -.04 & -0.12 \\
\hline & SA & -.19 & -.16 & -.33 & -0.26 \\
\hline & B & .08 & .07 & -.13 & 0.01 \\
\hline & IP & .20 & .22 & .36 & 0.29 \\
\hline \multirow{3}{*}{$\begin{array}{c}\text { Group TAT } \\
\text { (Reaction) }\end{array}$} & $\mathrm{AG}$ & .17 & .29 & .20 & 0.24 \\
\hline & $\mathrm{R}$ & -.21 & $-.42 *$ & -.22 & -0.30 \\
\hline & $\mathrm{F}$ & .09 & .16 & .04 & 0.10 \\
\hline \multirow{3}{*}{$\begin{array}{l}\text { Group TAT } \\
\text { (Outcome) }\end{array}$} & $\mathrm{H}$ & -.05 & -.09 & -.16 & -0.11 \\
\hline & $\mathrm{U}$ & -.17 & -.10 & -.02 & -0.11 \\
\hline & IF & .23 & .21 & .20 & 0.24 \\
\hline \multirow{3}{*}{$\begin{array}{l}\text { Group TAT } \\
\text { (Livelihood } \\
\text { domain) }\end{array}$} & S & -.21 & -.11 & $-.38 *$ & -0.27 \\
\hline & $\mathrm{H}$ & .21 & .00 & $.41^{*}$ & 0.24 \\
\hline & $\mathrm{F}$ & .11 & .22 & .12 & 0.16 \\
\hline
\end{tabular}

\section{Discussion}

\section{A. Correlation between Group TAT and Baum Test}

In the three-sheet Baum tests, the "Total Length of the Tree", "Length of Trunk", and "Height of Crown" were measured and the correlation coefficients were calculated to examine the relationship of those measured values with each factor of Group TAT.

Table 4 shows that the correlation with each factor in the group TAT was found only observed in the first sheet, which is considered to reflect the subject's "social self". It is worth noting that the TAT test implemented in this study did not use a conventional method, where the test is usually conducted individually, and the subjects respond to questions by telling stories freely. Instead, the test was implemented in groups, and the response was in the form of choosing predetermined options.

The option-based response can be implemented and interpreted easily and is characterized by a low degree of freedom of response, making it easy to suppress the free association of ideas of the subjects. On the other hand, since the subjects can easily decide their answers from the contents of the predetermined options, there is a possibility that the individual internal aspects of the subjects are hard to be reflected from the answers. The group test method is also easier to implement than the individual test method, but because the number of other subjects taking the test at the same time was large, the subjects might feel anxious on how they were perceived socially. Furthermore, since the projection method, represented by the TAT and Rorschach test, is interpreted through observation of the subjects' actions, such as facial expression and behavior during the test, and linguistic analysis, group implementation of the method and the use of predetermined options cause such an interpretation difficult.

Based on the above, it is considered that the Group TAT in this study only reflects the superficial part of the subjects, such as how they are perceived socially, rather than their deep personality tendency. Thus, it may be the reason why we could only observe the correlation of the first page of the Baum Test, which is said to reflect the subject's "Social Self", with the other tests. 
In addition, when we looked at the relationship between TAT and each factor for each subject individually, we found a positive correlation between "Total Length of the Tree" with "SA" and "S", and a negative correlation with "IP". This observation may mean that larger trees symbolize a greater desire for expansion, indicated by a stronger interest in society and a stronger desire to obtain approval from society. In contrast, smaller trees are considered to represent the tendency to avoid contact with society.

The "Trunk Length" correlated negatively with "H". The trunk is said to represent the strength of an individual's ego. A weak ego is thought to indicate a person's low resistance to adverse events, leading the person to avoid more negative outcomes and activate the mechanism to achieve a happy outcome even when it seems somewhat impossible.

The "Crown" correlated positively with "B (belonging)" and "S (Society)", and correlated negatively with "IP (Independence)" and "H (Home)". Based on the results of this study, the size of the Crown may represent a subject's contact and interest in society, and conversely, a smaller Crown may indicate that the subject is more interested in a safe place, such as the home. Crown can be regarded to show contact with society.

\section{B. Correlation with SRS-18}

The observed correlation with the Baum Test was a negative correlation between the "Total Length of the Tree" with SRS-18 total score. Also, a negative correlation was observed between the "Total Length of the Tree" and "Trunk Length" with "Irritability, anger". From the data, it is thought that the "Total Length of the Tree" indicates the overall emotional stability of a person. In addition, the lack of direct correlation between the Baum Test with SRS-18 's "Depression, anxiety" and "Helplessness" seemed to be caused by the fact that the Baum Test conducted in this study only reflected the "Social Self" based on the drawing on the first sheet, and does not reflect anxiety and self-confidence as well as dissatisfaction and frustration.

The observed correlations with TAT were negative correlations of "R (Regression)" with "Irritability, anger" and "S (Social)" and "Helplessness". Also, "H (Home)" showed a positive correlation with "Helplessness". The tendency that irritability and anger were not expressed is considered to be related to the tendency to stay inside. Also, it is thought that the higher the state of helplessness becomes, the easier it is for a person to turn his/her back from society and focus on the family or home where he/she feels safe.

\section{General Discussion}

Since the Group TAT was implemented in groups and the answers were based on options, and the SRS-18 was implemented as a self-completed questionnaire, it is considered that the two tests reflect the subject's tendency of superficial personality. Therefore, based on the results of this study, we could re-confirm the current interpretive hypothesis that the first sheet of Baum Test, which showed correlations with the two scales, represents the subject's "Social Self". Also, the ability to confirm that the length of the trunk in the Baum Test, which represents the level of self-awareness, is related to a person's emotional stability can be considered as a significant result.

On the other hand, since it was not possible to confirm the characteristics of the second and third sheets of Baum Tests in this study, they may need to be re-evaluated using a scale that can measure the depth of the subjects' minds. In addition, since all the measurements in the Baum Test performed in this study only used "length", it may be required to consider other factors, such as "thickness" and "position" in order to examine the meaning of Baum Test more precisely. In the future, we plan to find and select psychological tests that can reflect the levels indicated by 
the second and third sheets in Baum Test and reexamine the method to measure the trees drawn in Baum Test, and our future challenge is to verify the validity of the interpretive hypothesis of the three-sheet Baum Test method.

\section{Acknowledgement}

This study was conducted with the cooperation of Kenta Koshimura, Ren Yamamura, and Takuya Oizumi, who are graduates of the Faculty of Information Sciences and Arts Toyo University.

\section{References}

[1] H. Mukuta, and N. Komiya, "A Consideration on Pathology of Schizophrenia and Recovery Process in Baum Test", Journal of Osaka University of Economics, vol. 56, pp. 209-217, 2005. (in Japanese)

[2] Y. Murakami, "Internal changes of a child with developmental disabilities: through the projective drawing technique", The Bulletin of the Graduate School of Education of Waseda University, no. 18-2, pp. 179-189, 2010. (in Japanese)

[3] K. Tsunashima, "Personality Projection in the Drawing : Relationships between Indices of the Tree-Drawing Test and Scales of Y-G Personality Inventory”, Kawasaki medical welfare journal, vol. 2, pp. 87-96, 1992. (in Japanese)

[4] T, Ito, Y. Ide, T. Tanimoto, and Y. Nakano, "A relationshop between Baum test index and Y-G personality test", Annual convention of the Japanese Association of Educational Psychology, vol. 50, p. 741, 2008. (in Japanese) 